\title{
Habitat Suitability Evaluation of the Chinese Horseshoe Bat ( $R$. sinicus) in the Wuling Mountain Area Based on MAXENT Modelling
}

\author{
Xiang Luo ${ }^{1,2}$, Liang Liang ${ }^{1,3 *}$, Zhixiao Liu ${ }^{4 * *}$, Jiahui Wang ${ }^{1}$, \\ Ting Huang ${ }^{1}$, Di Geng ${ }^{1}$, Bingqian Chen ${ }^{1}$ \\ ${ }^{1}$ School of Geography, Geomatics and Planning, Jiangsu Normal University, Xuzhou, Jiangsu, China \\ ${ }^{2}$ Institute of Agricultural Engineering, Jiangxi Academy of Agricultural Sciences, Nanchang, Jiangxi, China \\ ${ }^{3}$ State Key Laboratory of Remote Sensing Science, Beijing, China \\ ${ }^{4}$ College of Biology, Jishou University, Jishou, Hunan, China
}

Received: 20 October 2018

Accepted: 27 December 2018

\begin{abstract}
The modelling of habitat suitability and the prediction of the spatial distribution of species are important for the conservation of endangered species. In this paper, the evaluation of habitat suitability of the Chinese horseshoe bat (Rhinolophus sinicus) in the Wuling Mountains was studied. The global positioning system (GPS), remote sensing (RS) and geographic information system (GIS) were used to obtain ground survey data and analyse the habitat factors driving the distribution of $R$. sinicus. The binary logistic regression model and the Maximum Entropy Model (MAXENT model) were used to analyse the habitat suitability of $R$. sinicus, and the receiver operating characteristic (ROC) curve was used to evaluate the models. The results showed that both models had high prediction accuracy, but the results of the MAXENT model were more stable than those of the binary logistic regression model when the sample size changed, indicating that the MAXENT model was the optimal method. Thena jack-knife test was used to determine the importance of the influencing factors. The results showed that the main factors influencing habitat selection were annual mean temperature, annual precipitation, the nearest distance from a settlement and vegetation fractional coverage (VFC). The suitable habitat was mainly distributed in the middle region of the study area. Marginally suitable habitat was located on the edge of suitable habitat, and unsuitable habitats were mainly distributed in the southern and northwestern regions.
\end{abstract}

Keywords: $R$. sinicus, habitat factors, MAXENT model, binary logistic regression model, habitat suitability

*e-mail: liang_rs@jsnu.edu.cn,

**e-mail: zxliu1965@163.com 


\section{Introduction}

Habitat is defined as the location where an organism lives and reproduces. Organisms always live in habitats with particular characteristics. Animal behaviour, population patterns and species interactions are closely related to habitats [1]. Habitat suitability refers to the potential ability of a habitat to support the survival of a species [2]. Habitat suitability has important significance to research on modelling habitat suitability and provides a scientific basis for the management of species protection plans [3]. In recent years, research on the suitability of wildlife habitat has received increasing attention.

The Chinese horseshoe bat (Rhinolophus sinicus) is a typical cave-dwelling species; this bat remains in caves during the day but flies outside the caves to prey on insects (most insects are agricultural and forestry pests, mainly Lepidoptera and Coleoptera) at night. The main habitats of $R$. sinicus are the Himalayas, China, and Vietnam [4]. In China, R. sinicus mainly lives to the south of the Yangtze River [5]. According to the 2016 World Conservation Union Red List [6], R. sinicus even has the status of least concern (LC) species due to habitat fragmentation and anthropogenic disturbance. Considerable research has been performed on the cytogenetics [7], predation and predation behaviour [8], habitat selection [9], and echolocation [10] of this species. However,a lack of research remains on the mechanism of habitat selection, the driving factors and the prediction of the spatial distribution of $R$. sinicus in the Wuling Mountains.

Bats are dependent on caves, and therefore most associated research has focused primarily on investigating caves to obtain point source information, including the geographical locations of caves, altitude and vegetation status [9]. However, such work is time consuming, laborious and inefficient. With the development of spatial information technology, animal habitats are monitored and mapped synchronously with " $3 \mathrm{~S}$ " technology, which includes global positioning system (GPS), remote sensing (RS) and geographic information system (GIS) technology. The 3S technology has advantages that include large-scale coverage and being fast and highly efficient, in addition to obtaining surface source information [11]. With the 3S technology, time and labour are saved in data acquisition, and the technology is also scientific and objective and can overcome previous limitations of artificial access to habitat data [1].

Species Distribution Models (SDMs) are an important method to study the habitat selection of species. These models are mainly related to species distribution data and environmental data and obtain the relationships between species distribution characteristics and habitat factors [12-15]. When an SDM is applied to a study area, the model estimates the distribution of the target species [16]. According to the data requirements and principles, SDMs can be divided into mechanistic
[17], regression [18-19] and niche [7, 20] models. A mechanistic model depends on the empirical knowledge of an expert, is subjective, and has certain limitations [21-22]. The regression models mainly include linear regression and logistic regression. The binary logistic regression model is often used to predict the distribution of species based on the presence and absence of point data [23-25]. Ecological niche models (ENMs) are based on specific algorithms and only use point data for areas where a species is located to assess the niche of a species. The Maximum Entropy Model (MAXENT model) is a niche model that provides suitable modelling effects for rare species that present narrow living spaces and for which only presence data are available [26-29]. In 2004, Phillips developed MAXENT software (Center for Biodiversity and Conservation, New York, NY, USA), which has been widely used to predict the suitable habitat area of species because of its high accuracy, high computational efficiency and ease of use [26-27, 30-32]. For example, Liu et al. [21], Akbar et al. [33] and Wordley et al. [34] used the MAXENT model to evaluate habitats for Cervus elaphus, blue sheep and bats, respectively.

In this paper, we combined the $3 \mathrm{~S}$ technology and optimal SDM method to evaluate the habitat suitability of $R$. sinicus in the Wuling Mountain area from the perspective of multisource data. This approach can be used to identify high-priority areas for conservation and to provide important theoretical guidance for the conservation of species and maintenance of species diversity. Specifically, our objectives were to (1) assess the effectiveness of the SDM in determining the potential distribution of $R$. sinicus, (2) identify the areas that need priority protection, and (3) obtain the main factors that influence the habitat suitability of $R$. sinicus in the Wuling Mountain area.

\section{Experimental Approach}

\section{Study Area}

The study area spanned the main distribution area of $R$. sinicus $\left(25^{\circ} 52^{\prime}\right.$ to $31^{\circ} 24^{\prime} \mathrm{N}$ and $107^{\circ} 04^{\prime}$ to $112^{\circ} 02^{\prime} \mathrm{E}$ ) and encompassed four administrative provinces and cities (Hunan, Hubei, Chongqing and Guizhou; Fig. 1). The total area was approximately 0.17 million $\mathrm{km}^{2}$ with an average elevation of $700 \mathrm{~m}$ and an average slope of $15^{\circ}$. The climate in this region is a transition zone from subtropical to warm temperate, the annual average temperature is $13.5 \sim 17.0^{\circ} \mathrm{C}$, and the total annual precipitation is between 1100 and $1600 \mathrm{~mm}$. The forest cover types in this area are mainly coniferous and broad-leaved mixed forest and evergreen coniferous forest, and the average forest coverage is $56 \%$, which is much higher than the national average of $20.36 \%$ [35]. The carbonate karst caves in this region are well developed. The study area is one of the main distribution areas of bats in China [36]. 


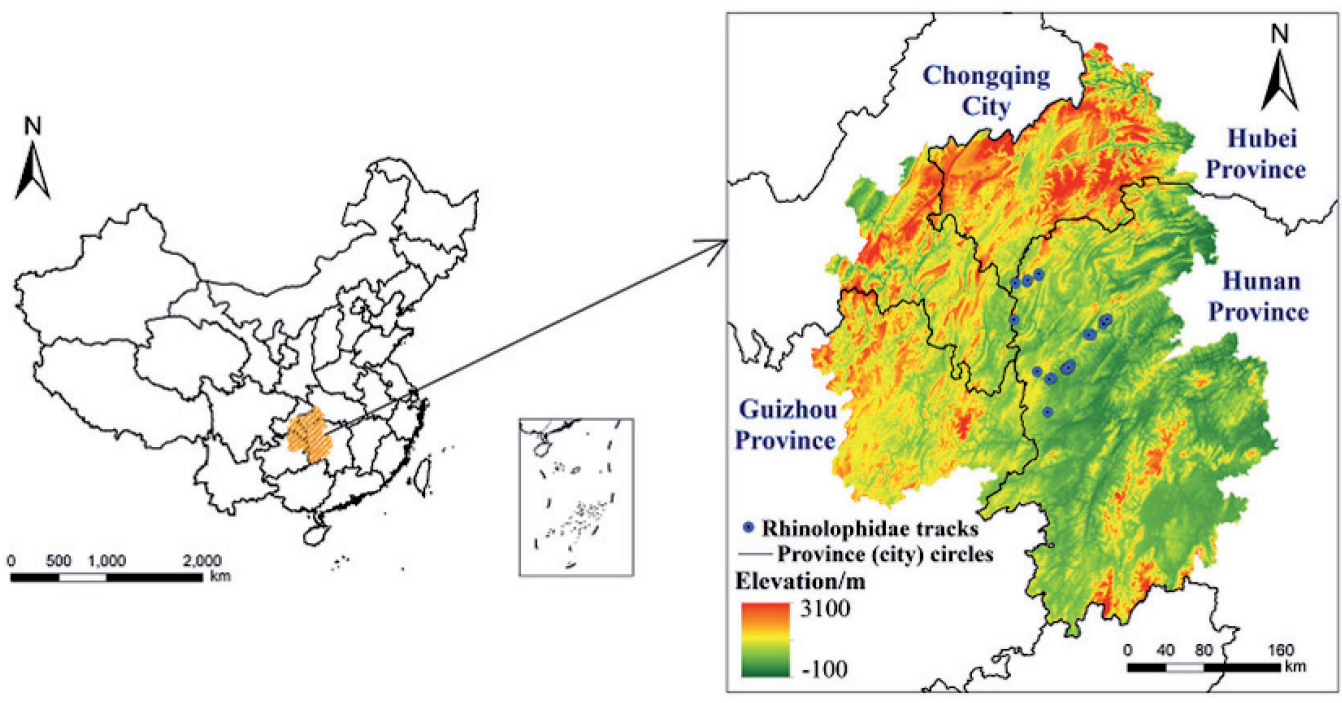

Fig. 1. Overview of the study area; the background colours indicate the elevation of the study area and the points are survey points from 2015 to 2017; the figure was created with ArcGIS10.2.

\section{Materials and Methods}

\section{Species Occurrence Data Collection}

From January 2015 to April 2017, wild cave surveys were conducted in the Wuling Mountain area by visiting local residents and guides. The characteristics of $R$. sinicus activity were obtained with observations and the recording of the excrement, food trails, naturally dead individuals, and living individuals in the caves. Bats were captured with mist nets or by hand out of their day roosts. For captured bat individuals, we recorded the sex, measured the morphological characters, and then identified the bat species. A total of 55 caves were investigated, of which 29 had $R$. sinicus activities (Fig. 1). In this paper, we observed and recorded the habitat information inside and around the caves, a GPS device (Garmin International, Inc., Olathe, Kansas, USA) was used to measure and record the geographical location of each cave, and ArcGIS10.2 (ESRI, Redlands, California, USA) was used to generate survey point vector data.

Habitat factors. A number of abiotic, biotic, and anthropogenic factors can influence the quality and availability of species habitats $[17,37]$. In order to explore the modelling of $R$. sinicus habitat suitability, we selected 10 factors from among four categories of habitat factors: vegetation factors, topographic feature factors, meteorological factors and anthropogenic disturbance factors.

Vegetation factor. This study used vegetation fractional coverage (VFC) as the vegetation factor. With RS data, thematic maps of vegetation indices can be obtained [38-43]. In this study, the data mainly contained the outliers removed normalized difference vegetation index (NDVI) based on the Landsat 8 OLI data from 2015 to 2017, which were obtained from the
Geospatial Data Cloud. Based on the NDVI data, a dimidiate pixel model was used to retrieve the VFC map of the study area.

Topographic feature factors. Topographic feature factors include elevation, slope and aspect [1, 44]. A digital elevation model (DEM) can be used to characterize topographic features. In this paper, DEM data were obtained from a GDEM DEM downloaded from the Geospatial Data Cloud at a $30 \mathrm{~m}$ spatial resolution. The slopes and aspects were calculated using the GIS spatial analysis module.

Meteorological factors. The annual mean temperature and annual precipitation were the meteorological factors. After pretreatment, the annual mean temperature and annual precipitation were extracted. The meteorological data were downloaded from the global meteorological data set of the World Clim Version 2 of the World Meteorological Database (http://www.worldclim.org/).

Anthropogenic disturbance factors. The anthropogenic disturbance factors were the nearest distances from roads, rivers, settlements and farmland [45-46]. Land use data reflect the state and distribution characteristics of land use factors. The land use data were obtained from the global surface coverage data product Globe Land 30, which was downloaded from the Global Landcover website. The data for rivers, farmland and settlements were subsequently extracted from the land use data. The road vector data were downloaded from the DIVA-GIS website. The Euclidean distance calculation method was used to obtain the nearest distance to roads, rivers, farmland and settlements at each point $(30 \times 30 \mathrm{~m}$ grid $)$ of each study area.

Collinearity is the linear correlation among independent factors, and it reduces the predictive accuracy of a model. To reduce the influence of collinearity on the final results of a model, one of the factors is removed according to its ecological 
significance when the correlation coefficient between two factors is greater than 0.75 [47]. In this study, based on the correlation analysis, the correlation coefficients between any two factors were less than 0.75 , indicating that collinearity did not occur between the factors; therefore, none of the factors were removed.

To meet the requirements of the data format of the MAXENT model, ArcGIS10.2 software was used to unify the boundaries of all environmental variable layers, and the coordinate system was unified into WGS-1984-Albers. The grid size was unified to $30 \times 30 \mathrm{~m}$.

\section{Species Distribution Modelling}

A binary logistic regression model is a multivariate analysis model used to study the relationships between two categories of observation results and the influencing factors. In recent years, the binary logistic regression model has been widely used to study and predict habitat selection of species because this model can accurately predict the probability of occurrence [24-25]. In this study, the factors selected based on the correlation and difference analyses were used for the modelling. We extracted the values of habitat factors corresponding to each surveyed spot with the ArcGIS10.2 software. Based on the 55 surveyed sites, habitat factors were entered as independent variables in different combinations, with $R$. sinicus presence/absence entered as the dependent variable, and all possible models were implemented with the SPSS 18.0 statistical software package. The binary logistic regression model was as follows $[25,48]$ :

$\operatorname{Logit} \frac{P(Y=1)}{1-P(Y=1)}=\alpha+\beta_{1} x_{1}+\beta_{2} x_{2}+\beta_{3} x_{3}+\cdots+\beta_{i} x_{i}$

...where $\alpha$ is a constant of the equation, $x_{i}$ is a predictor factor, and $\beta_{i}$ is the coefficient of the predictor factor.

A niche model is based on the species distribution data and the corresponding environmental data collected during field surveys that form the training samples. According to certain algorithms, a model is constructed to predict the ecological needs of a species and to project the results into different time and space points to predict the potential distribution of that species [49]. The MAXENT model is an SDM based on the maximum entropy theory. The habitat suitability of each point in the whole study area can be predicted by the training data of a species distribution, which is then combined with the environmental data in the study area [21]. Moreover, the modelling effect of the MAXENT model on small samples is better than that of other modelling methods [26-27, 32].

\section{Modelling}

Binary logistic regression model. The habitat factors were used to establish all possible logistic regression models. The AIC can be used to determine the significant differences among different models and can comprehensively weigh the relationship between the applicability of a model and the number of parameters. The $A I C_{C}$ is an improved $A I C$ that can better reduce the deviation, which is used to select the most reasonable regression model. The $W_{i}$ provides a standardized score for all possible models. In this study, $A I C_{C}$ and $W_{i}$ were used to select the most appropriate regression model and determine the primary factors of influence. First, the model with the smallest $A I C_{C}$ value was selected as the optimal model, and the factors contained in the model were considered to be the main factors of influence. Second, any models within $\triangle A I C_{C}<2.0$ of the optimal model were considered as acceptable [50]. Third, the weighted coefficients of the main influencing factors in these models were summed to obtain the final coefficients of the main factors of influence. Finally, the logistic regression model was established. In the ArcGIS10.2 software, with the thematic maps of the main factors of influence used as the input variables in the established model, a grid was calculated to predict the spatial distribution of $R$. sinicus.

MAXENT model. Under the constraints of environmental variables, the MAXENT 3.3.3 software considers the maximum entropy of a system and predicts the possible distribution areas of a species after several iterations. In this paper, the $R$. sinicus distribution data and environmental data were introduced into MAXENT 3.3.3, and we selected $75 \%$ of the distribution data for model training and $25 \%$ for model testing. In this study, jack-knife analyses were used to determine the importance of environmental variables during the modelling process [51].

The results predicted by the MAXENT model are in ASCII format. The value of each point in a layer represented the probability that $R$. sinicus may appear in the region, with the range of values from 0-1 [26]. Low probability values correspond to a smaller likelihood that a species will appear in a grid unit, whereas high probability values indicate a greater likelihood that a species will appear in a grid unit. For further analysis, the results were converted to raster data in order to obtain the spatial distribution prediction map. Using the classification criteria in Rahumutulla et al. [2], Qin et al. [26], Wang et al. [49] and Yang et al. [52], habitat suitability was divided into three grades using the reclassification tool in the ArcGIS10.2 software (Table 1).

\section{Model Evaluation}

The area under the curve (AUC) of the receiver operating characteristic (ROC) curve was used to evaluate the predictive power of the models. Because the AUC value is not affected by the diagnostic threshold and is insensitive to species, the value is considered the best model predictive index [53]. The AUC values range from 0 to 1 . An AUC value of 0.5 indicates 
Table 1 . Suitability classification of potential distribution areas.

\begin{tabular}{|c|c|}
\hline Suitability grade & $\mathrm{P}$ \\
\hline Unsuitable & $0-0.15$ \\
\hline Marginally suitable & $0.15-0.5$ \\
\hline Suitable & $0.5-1$ \\
\hline
\end{tabular}

Note: $\mathrm{P}$ is the probability that the species will occur in each grid unit.

a random prediction, and an AUC value of 1 indicates that the model predictions are consistent with the actual distribution of a species. A model with an AUC value above 0.75 is considered potentially useful [3, 26, 53-54].

In addition, in this paper,the influence of sample size on the model was determined to evaluate the stability of the model. First, all survey data points were randomly divided into 6 groups. The number of samples in each group was 9, 18, 27, 36, 45 and 55. Then, each group was used as a training sample for the modelling. Finally, the variation in the accuracy of each model with different sample sizes was obtained.

\section{Results and Analysis}

\section{Prediction Accuracy and Stability Evaluation of the Model}

In this paper, the ROC curve was used to test model accuracy. Fig. 2 shows the ROC curve obtained from the established model. The AUC value of the binary logistic regression model was 0.947 (Fig. 2a). The AUC values of the training set and the testing set of the MAXENT model were 0.984 and 0.973, respectively (Fig. 2b). Based on the AUC analysis, the MAXENT model showed high accuracy to predict the potential range distribution of $R$. sinicus.

Fig. 3a) shows the variation in the accuracy of the binary logistic regression model with sample size. As shown in the figure, the prediction accuracy of the binary logistic regression model increased in a certain range of sample sizes, with the accuracy of the model showing little change beyond that range. Therefore, the sample size had a large impact on the model and demonstrated poor model stability.

Fig. 3b) shows the variation in the accuracy of the MAXENT model with sample size. The corresponding AUC values of the MAXENT model remained relatively stable with the change in sample size, and the AUC values were all greater than 0.97 , indicating that the model was stable and not affected by the sample size.

\section{Habitat Suitability Distribution of $R$. sinicus}

Through the above comparative analysis, we see that the binary logistic regression model had high prediction
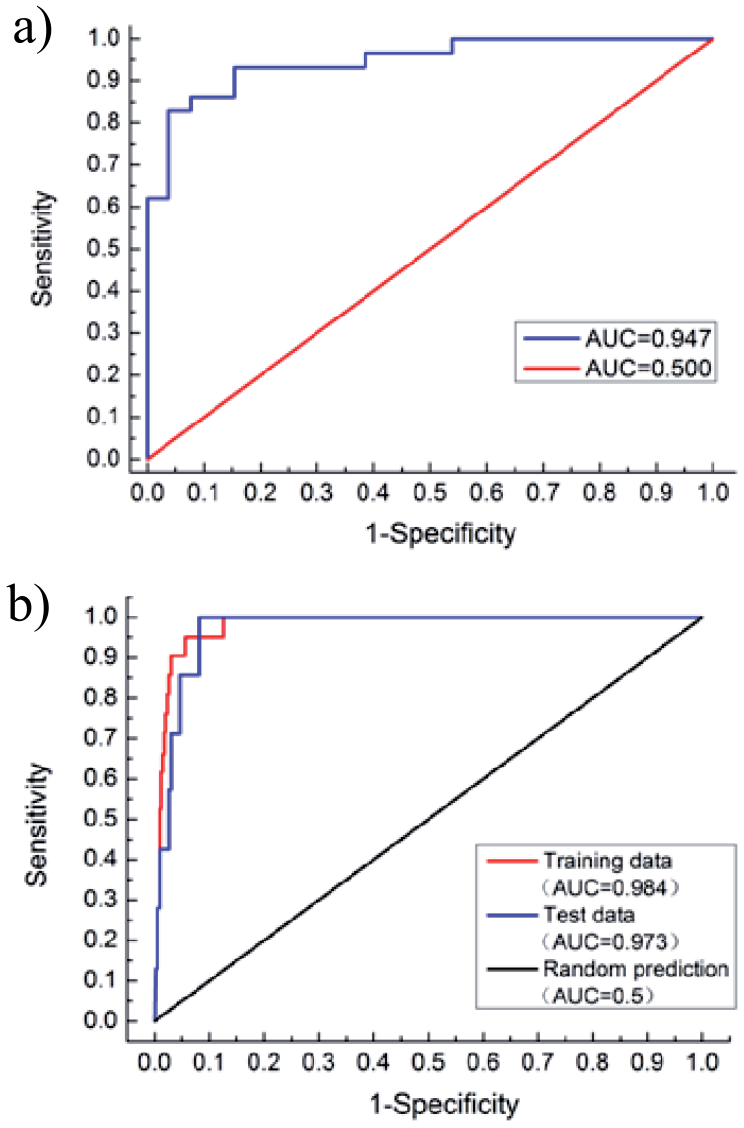

Fig. 2. ROC curve and AUC of habitat evaluation.

a)

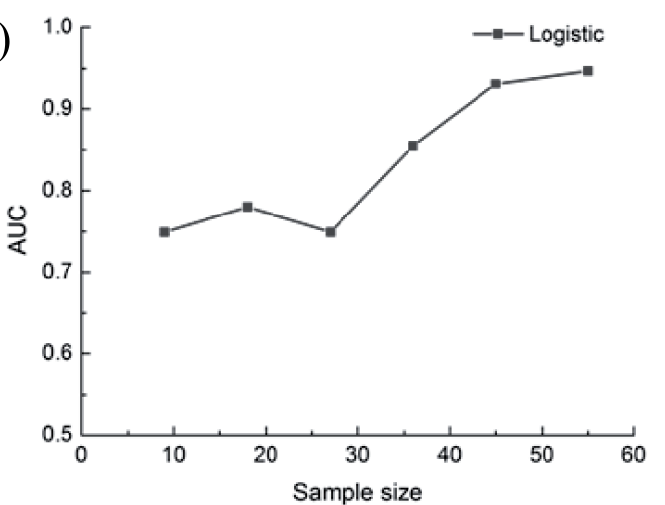

b)

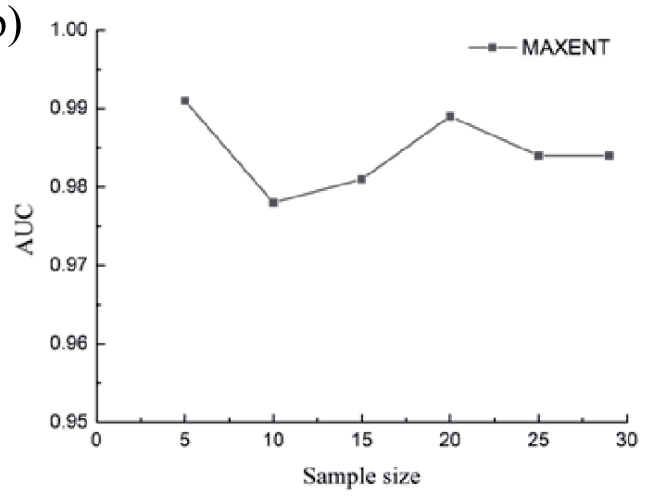

Fig. 3. Changes in the AUC value of the models with the sample size: a) binary logistic regression model and b) MAXENT model. 


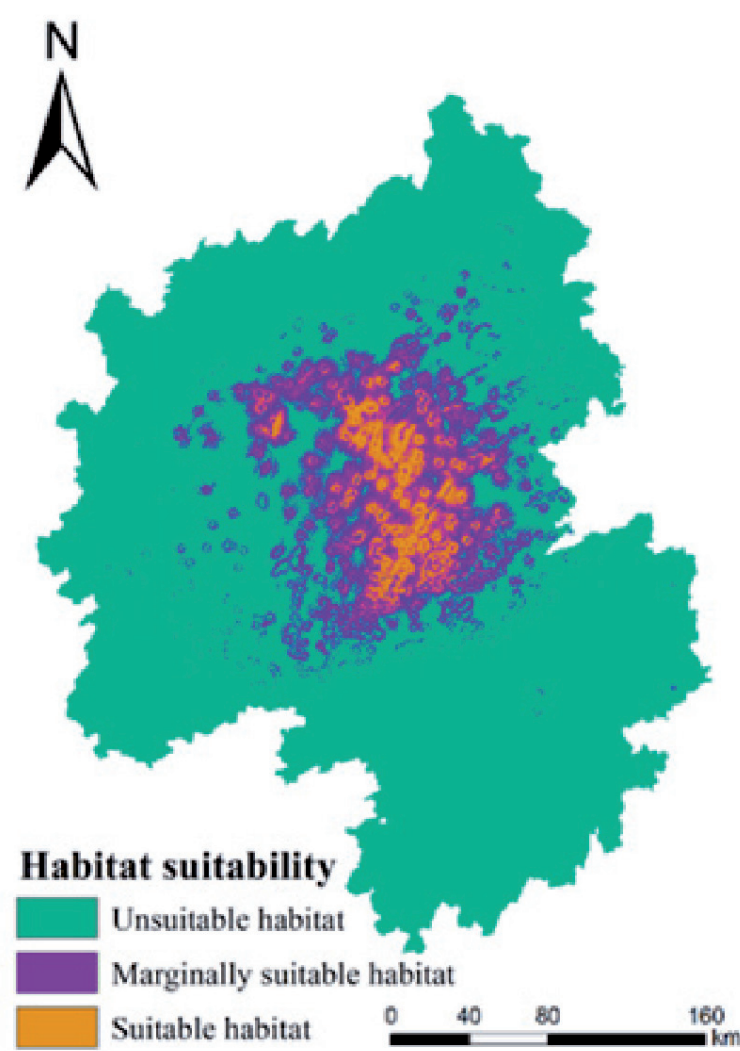

Fig. 4. Habitat suitability distribution.

accuracy but poor stability. However, the MAXENT model had not only high prediction accuracy but also good model stability. Therefore, the MAXENT model performed better than the binary logistic regression model.

In this paper, the MAXENT model results were used to analyse the habitat suitability of $R$. sinicus. According to the classification method in Table 1, the habitat of $R$. sinicus in the Wuling Mountain area was divided into unsuitable habitat, marginally suitable habitat and suitable habitat (Fig. 4). As shown in

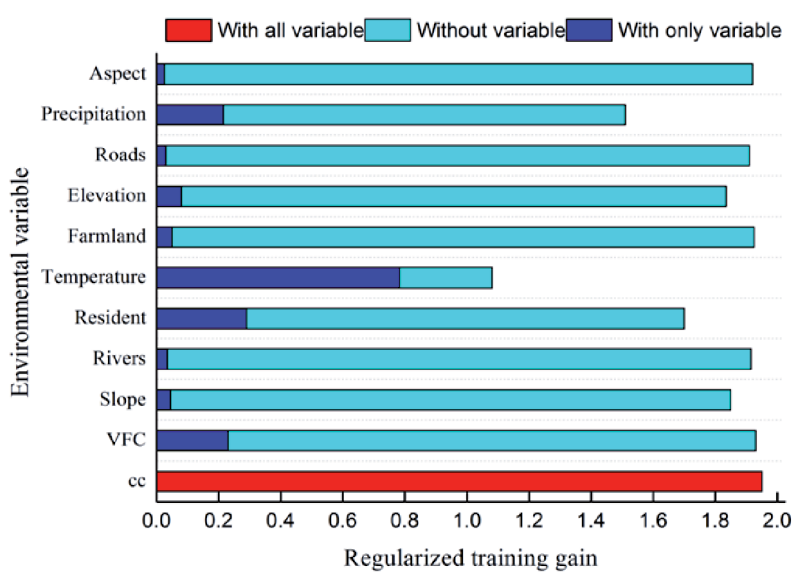

Fig. 5. Jack-knife test for evaluating the relative importance of environmental variables.
Fig. 5, the distribution of $R$. sinicus was mainly concentrated in the middle of the Wuling Mountains. Marginally suitable habitat was mainly concentrated at the edge of the suitable habitat range, and the unsuitable habitat was distributed in the southern and northwestern regions of the Wuling Mountains area. The statistical analysis showed that the total area of unsuitable habitat was $127233.33 \mathrm{~km}^{2}$, accounting for $74 \%$ of the study area; the total area of marginal habitat was $38514.36 \mathrm{~km}^{2}$, accounting for $22.4 \%$ of the study area; and the total area of suitable habitat was $6195.86 \mathrm{~km}^{2}$, accounting for $3.6 \%$ of the study area.

\section{Importance Analysis of Habitat Factors}

In this paper, the contribution rate of environmental variables was estimated by a jack-knife method to determine the optimal environmental parameters or the importance of each environmental variable. The results are shown in a histogram (Fig. 5). Fig. 5 shows that the main habitat factors that affected the potential distribution of $R$. sinicus were annual mean temperature, annual precipitation, the nearest distance from a settlement and the VFC.

Based on MAXENT 3.3.3, the model was established using the environmental variables to locate the potential suitable distribution of $R$. sinicus. The MAXENT model automatically output the contribution rate for each variable (Table 2). Table 2 shows that the contribution rates of distance from annual mean temperature, annual precipitation, the nearest distance from a settlement and the VFC were high at 48.1, 18, 12.8 and $7.1 \%$, respectively. The total contribution rate of these factors was $86 \%$, and this value could describe the habitat characteristics of $R$. sinicus. The contribution

Table 2. Contribution rate of environmental factors to model prediction

\begin{tabular}{|c|c|}
\hline Variables & Percent contribution (\%) \\
\hline Annual mean temperature & 48.1 \\
\hline Annual precipitation & 18 \\
\hline Settlement & 12.8 \\
\hline VFC & 7.1 \\
\hline Slope & 3.5 \\
\hline Elevation & 3.2 \\
\hline Farmland & 2.8 \\
\hline Roads & 2.3 \\
\hline Rivers & 1.3 \\
\hline Aspect & 1 \\
\hline
\end{tabular}

Note: The percent contribution is the contribution rate of each variable to the model during the training process, which depended on the particular path that the MAXENT model used to obtain the optimal solution. 
rates of the slope, elevation, aspect and the distances from roads, farmland and rivers were small, with percentage contributions of $3.5,3.2,1.0,2.3,2.8$ and $1.3 \%$, respectively.

\section{Influence of Habitat Factors on Habitat Suitability}

The MAXENT model uses the response curves to characterize the effect of each environmental variable on the probability of habitat distribution. Fig. 6 shows the response of the habitat distribution probability to the major factors of influence. Fig. 6a) shows the response curve of the occurrence probability of $R$. sinicus to annual mean temperature. As shown in the figure, the probability of habitat distribution of $R$. sinicus increased with increasing average annual temperature when the average temperature was less than $13.3^{\circ} \mathrm{C}$. However, when the average temperature was higher than $13.3^{\circ} \mathrm{C}$, the probability of habitat distribution of $R$. sinicus decreased with an increase in the annual average temperature, indicating that the average annual temperature had a great impact on the habitat of $R$. sinicus. At the same time, the probability of habitat distribution of $R$. sinicus was greater than 0.3 when the average mean temperature range was $12.6 \sim 13.5^{\circ} \mathrm{C}$, indicating that this temperature range was the most suitable for the survival and activity of $R$. sinicus.

Fig. 6b) shows the response curve of the occurrence probability of $R$. sinicus to annual precipitation. As shown in the figure, the probability of habitat distribution of $R$. sinicus increased gradually with the increase in annual precipitation until the annual precipitation reached $1400 \mathrm{~mm}$. At that level of precipitation, the probability of habitat distribution of $R$. sinicus reached the maximum of 0.61 . When the precipitation was greater than $1400 \mathrm{~mm}$, the curve tended to stabilize, and the distribution probability of $R$. sinicus did not change further. These results indicated that $R$. sinicus tended to be active in areas with high humidity; that is, $R$. sinicus preferred dark and humid areas [47].

Fig. 6c) shows that the distance from a settlement was the largest disturbance factor affecting $R$. sinicus, and the probability of habitat distribution of $R$. sinicus increased with the distance from a settlement. The probability of habitat distribution increased from 0 to 0.86 when the distance from a settlement was less than $2.5 \mathrm{~km}$, and the probability of habitat distribution reached the maximum value when the distance from a settlement was $2.5 \mathrm{~km}$. This result indicated that human disturbance greatly influenced the habitat of $R$. sinicus and that smaller distances from residential areas corresponded to stronger disturbances and a lower probability that $R$. sinicus would be present. When the distance from a settlement was more than $2.5 \mathrm{~km}$, the habitat distribution probability decreased. This result may be because the areas far from the residential areas were mainly mountainous areas, and as the vegetation structure became increasingly complex and gradually became the dominant factor, the impact of settlement
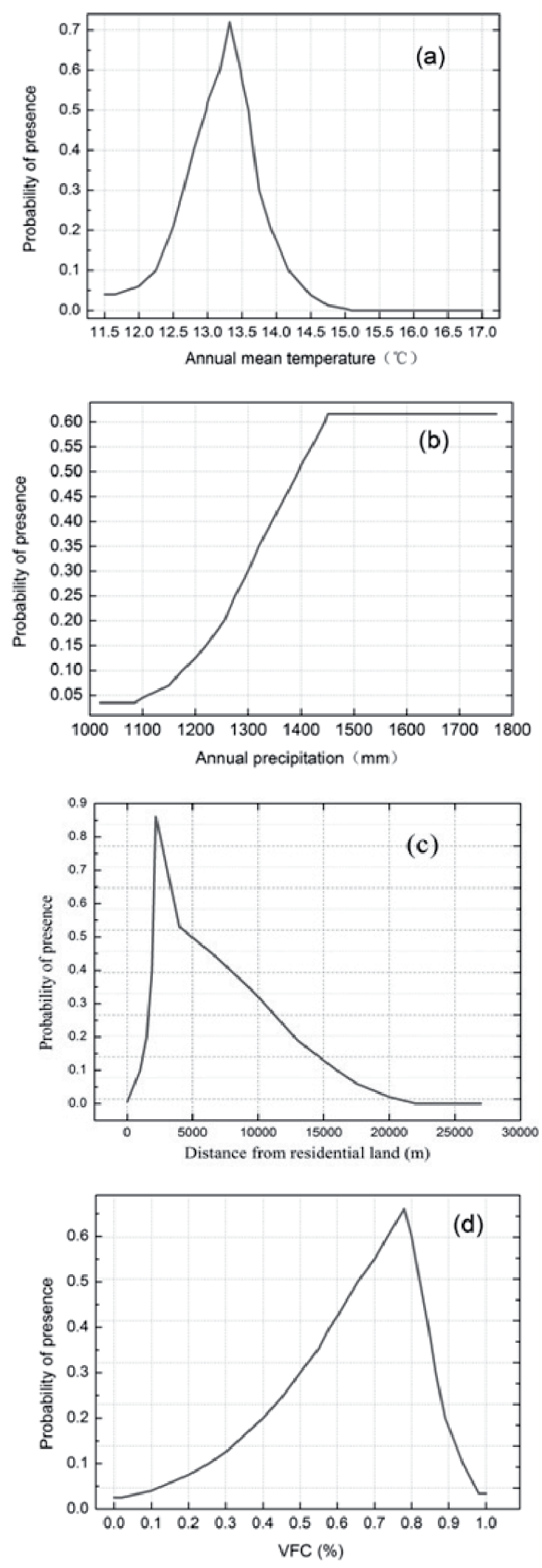

Fig. 6. Important factor response curves of the response of $R$. sinicus to: a) annual mean temperature, b) annual precipitation, c) the distance from a settlement and d) the VFC. 
on $R$. sinicus was not significant, and then vegetation structure greatly influenced the probability of $R$. sinicus occurrence.

Fig. 6d) shows the response curve of the habitat distribution probability to the VFC. As shown in the figure, the probability of habitat distribution of $R$. sinicus increased with increasing VFC when the VFC was less than $78 \%$. When the VFC was more than $78 \%$, the habitat distribution probability of $R$. sinicus decreased significantly. At the same time, the probability of habitat distribution of $R$. sinicus was greater than 0.3 when the VFC range was $50 \sim 86 \%$, indicating that this VFC range was the most suitable for the survival and activity of $R$. sinicus.

\section{Discussion}

SDMs mainly include mechanistic models, regression models and niche models. In this paper, the binary logistic regression model and the MAXENT model were used to evaluate the suitability of the habitat of $R$. sinicus in the Wuling Mountain area. When the accuracy of the two models was compared, the results of the comparison indicated that the MAXENT model was superior to the binary logistic regression model. The reason for the superiority of the MAXENT model may be that the binary logistic regression model needspresence-absence data of a species. However, the point data for the absence of an appearance cannot be guaranteed; thus, the reliability of the data cannot be ensured, which results in the deviation of the model results $[22,30]$. The MAXENT model only requirespresence data for a species to verify the model, and these data are more credible.

The MAXENT model determined the importance of the associated variables using a jack-knife method [26]. The results showed that annual mean temperature, annual precipitation, the nearest distance from a settlement and the VFC were the main habitat factors affecting $R$. sinicus habitat distribution, whereas the aspect, slope, and distances from roads, farmland and rivers had less influence on the habitat distribution of $R$. sinicus.

Regarding the meteorological factors, annual mean temperature was an important variable affecting the presence of $R$. sinicus. The occurrence probability of $R$. sinicus increased with an increase in annual mean temperature and then decreased. This result indicated that the annual mean temperature affected the habitat selection of $R$. sinicus, and the most suitable temperature range was $12.6 \sim 13.5^{\circ} \mathrm{C}$. Temperature affects the predatory activity of $R$. sinicus by affecting the insect richness. At the same time, annual precipitation was also a main factor influencing habitat selection of $R$. sinicus. Rhinolophus sinicus prefers high-humidity areas, and the annual precipitation can affect the activity of $R$. sinicus by affecting the environmental humidity. Wang [1] found that bat activity was affected by temperature and humidity, consistent with the results of this study.

The distance from a settlement was an important disturbance factor in the spatial distribution of $R$. sinicus habitat suitability. When the distance from a settlement was less than $2.5 \mathrm{~km}, R$. sinicus habitat distribution probability increased gradually with the increasing distance from the settlement. This result indicated that the disturbance effect of a nearby settlement was large; thus, these areas were not suitable for the activity of $R$. sinicus. Gaisler et al. [55] found that the number of bat habitats was negatively correlated with the distance from city centres, which corroborates these results. When the distance from a settlement was more than $2.5 \mathrm{~km}$, the habitat distribution probability decreased, indicating that the influence of other habitat factors played a leading role. The results showed that the response curve of $R$. sinicus to settlement was similar to that of previous results. For example, Zhang et al. [47] studied the suitability of Nipponia nippon breeding habitat and showed that the probability that $N$. nippon would be present initially increased and then decreased with an increase in the distance from roads. Zhou [22] showed that the probability of the presence of redcrowned crane initially increased and then decreased with an increase in the distance from settlements. The results also showed that the distances from roads, rivers and farmland were correlated with disturbances in the activities of $R$. sinicus. Gerald and Markus [46] showed that roads can directly or indirectly reduce the number of animals and interfere with animal activities. Wang noted that rivers could affect the predation and drinking water activities of species [1]. Kelly et al. [45] showed that the enhancement of agricultural production largely limited the ability of farmland to support other species and suggested that agriculture had a negative impact on the activities of bats and other species, which is consistent with the results of this paper. In summary, human activities have had a long and profoundly negative impact on the suitability of $R$. sinicus habitat, and this finding should attract public attention.

The importance analysis showed that the VFC was an important factor. The occurrence probability of $R$. sinicus increased with the increase in annual mean temperature and then decreased. This result indicated that the VFC affected the habitat selection of $R$. sinicus, and the most suitable VFC was in the range 50 86\%. Bats respond differently to vegetation structure depending on their predation strategy, ecological characteristics, and wing shape, with bats that exhibit low manoeuvrability preferring open areas and those that exhibit high manoeuvrability preferring complex zones [56]. R. sinicus belongs to Microchiroptera, and these animals are small and highly manoeuvrable and therefore prefer a complex zone with a high VFC; however, when the VFC was too high, the habitat was not suitable for $R$. sinicus activities.

In this study, the terrain factor had no significant effect on the habitat selection of R.sinicus, but the 
terrain factor also had an effect on the habitat suitability of $R$. sinicus. Rhinolophus sinicus is a typical cavedwelling species with a strong dependence on caves, and elevation and slope can determine the formation of caves $[1,57]$. Moreover, $R$. sinicus usually lives in places where they can be in complete darkness in order to avoid the light, and the aspect can change the light intensity, thereby affecting the distribution of suitable habitats for $R$. sinicus.

Based on the $3 \mathrm{~S}$ technology and statistical methods, this study analysed the modelling of suitable habitat for $R$. sinicus and then predicted the habitat suitability of $R$. sinicus using the MAXENT model. The point data of $R$. sinicus were obtained by artificial field investigation; however, because of the large size and complex terrain of the study area, the accessibility of points was affected. In the future, we will provide more complete species occurrence data.

\section{Conclusions}

The study of habitat suitability is of great significance for the conservation and maintenance of species diversity, and the analysis of the habitat requirements of a species and their relationships with environmental factors can clarify the distribution characteristics of the habitat of a species. Based on the survey point data and environmental data of $R$. sinicus, the habitat suitability of $R$. sinicus in the Wuling Mountains was studied using a binary logistic regression model and the MAXENT model, and the main conclusions are as follows:

1) According to the model evaluations, we found that both models had high prediction accuracy, but the model stability of the MAXENT model was better than that of the binary logistic regression model.

2) The model predictions showed that the distribution of $R$. sinicus was mainly concentrated in the middle of the Wuling Mountains. Marginally suitable habitat was mainly concentrated at the edge of the suitable habitat range, and the unsuitable habitat was distributed in the southern, western and northern regions.

3) The jack-knife test results showed that the main factors influencing habitat suitability were annual mean temperature, annual precipitation, the nearest distance from a settlement and the VFC. Rhinolophus sinicus preferred areas far from settlements and with abundant precipitation. For $R$. sinicus, the suitable annual mean temperature for survival was between 12.6 and $13.5^{\circ} \mathrm{C}$, and the suitable VFC was between 50 and $86 \%$.

\section{Acknowledgements}

The authors particularly thank NASA for providing the basic data (including the Landsat series data and the ASTER GDEM data) and the NGCC for providing the Globe Land 30 data.

\section{Funding}

The National Natural Science Foundation of China (Nos. 31560130 and 41401473), the Natural Science Foundation of Jiangsu Province (BK20181474, BK20160218), the Open Fund of State Key Laboratory of Remote Sensing Science (OFSLRSS201804), the Project Funded by the Priority Academic Program Development of Jiangsu Higher Education Institutions (PAPD), and the Postgraduate Research and Practice Innovation Program of Jiangsu Province (KYCX18 2157) supported this research.

\section{Conflict of Interest}

The authors declare that they have no conflicts of interest to disclose.

\section{References}

1. WANG J. Habitat selection and prediction of spatial distribution in Greater Horseshoe Bats, Rhinolopinus ferrumquinum at multiple spatial scales. Dissertation, Northeast Normal University, Changchun, Jilin, China, 2009 [In Chinese].

2. WANG X.L. Landscape dynamics and suitability assessment of Przewalski's Gazelle habitat. Master's Thesis. Chinese academy of forestry sciences, Beijing, Beijing, China, 2004 [In Chinese].

3. RAHUMUTULlA A., GUZALNUR Z., XU Z. L., EZIZJAN N., ABDULKEYUM A., DILSHAT A., MAHMUT H. Assessment of habitat suitability for Gazellasubgutturosa in the Ebinur reserve. Acta Ecologica Sinica, 36, 4171, 2016.

4. XIE L.F., SUN K.P., JIANG T.L., LIU S., LU G.J., JIN L.R., JIANG F. The effects of cultural drift on geographic variation in echolocation calls of the Chinese rufous horseshoe bat (Rhinolophus sinicus). Ethology. 123, 532, 2017.

5. WANG Y.X. A complete checklist of mammal species and subspecies in China, a taxonomic and geographic reference. China Forestry Publishing House, Beijing, Beijing, China, 2003 [In Chinese].

6. The IUCN red list of threatened species. Available online: http://www.iucnredlist.org (accessed on 01 January 2016).

7. XU Z.L., PENG H.H., PENG S.Z. The development and evaluation of species distribution models. Acta Ecologica Sinica. 35 (02), 557, 2015 [In Chinese].

8. MIKOVÁ E., VARCHOLOVÁ K., BOLDOGH S., UHRIN M. Winter diet analysis in Rhinolophuseuryale, (Chiroptera). Central European Journal of Biology. 8, 848, 2013.

9. YU W.H., FAN F.L., JIANG H.S., LI S.Y., KONG X.K., WU Y. Habitat selection of cave-bats in summer in wuzhi mountain, Hainan. Guangdong Forestry Science and Technology. 31 (05), 74, 2015 [In Chinese].

10. ZHANG X.N., WANG S.W., FENG J., HU X.L., LIU Y., HE X.H., SHI L.M. Recognition method of wavelet packets for echo-locating calls of flying rhinolophuslepidus and rhinolophusrouxi. Technical Acoustics. 27 (01), 44, 2008 [In Chinese]. 
11. CHEN W.X., YANG X.R., LI Z.Q. The analysis of forest landscape patterns in east dongting lake region based on 3S technology. Chinese Agricultural Science Bulletin. 31, 1, 2015 [In Chinese].

12. ANDERSON R.P., MARTINEZ-MEYE R. Modeling species' distributions for preliminary conservation assessments: an implementation with the spiny pocket mice (Heteromys) of Ecuador. Biological Conservation, 116, 167, 2004.

13. ELITH J., LEATHWICK J. Species distribution models: ecological explanation and prediction across space and time. Annual Review of Ecology Evolution \& Systematics, 40, 677, 2009.

14. PETERSON A.T., SOBERÓN J., PEARSON R.G., ANDERSON R.P., MARTÍNEZMEYER E., NAKAMURA M. Ecological niches and geographic distributions. Princeton University Press, Princeton, NJ, 2011.

15. WILSON C.D., ROBERTS D., REID N. Applying species distribution modelling to identify areas of high conservation value for endangered species: a case study using Margaritifera margaritifera (L.). Biological Conservation. 144, 821, 2011.

16. LI G.Q., LIU C.C., LIU Y.G., YANG J., ZHANG X.S., GUO K. Advances in theoretical issues of species distribution models. Acta Ecologica Sinica. 33, 4827, 2013[In Chinese].

17. FAN J.T., LI J.S., XIA R., HU L.L., WU X.P., LI G. Assessing the impact of climate change on the habitat distribution of the giant panda in the Qinling Mountains of China. Ecological Modelling, 274, 12, 2014.

18. LI H.Q., LIAN Z.M., CHEN C.G. Wintering habitat selection by Brown-Eared Pheasant (Crossoptilon mantchuricum) in Huanglong Mountains Nature Reserve, Shanxi Province, China. Scientia Silvae Sinicae, 46 (06), 102, 2010 [In Chinese].

19. GOITI U., GARIN I., ALMENAR D., SALSAMENDI E., AIHARTZA J. Foraging by Mediterranean Horseshoe Bats (Rhinolophus euryale) in Relation to Prey Distribution and Edge Habitat. Journal of Mammalogy. 89, 493, 2015.

20. RODRIGO A.D.S, PAULO D.M.J. The use of species distribution models to predict the spatial distribution of deforestation in the western Brazilian Amazon. Ecological Modelling, 291, 250, 2014.

21. LIU Z.S., GAO H., TENG L.W., SU Y., WANG X.Q., KONG F.Y. Habitat suitability assessment of blue sheep in Helan Mountain based on MAXENT modeling. Acta Ecologica Sinica, 33 (22), 7243, 2013 [In Chinese].

22. ZHOU H. T. Habitat suitability assessment of Red-crowned Crane in Zhalong Nature Reserve based on MAXENT modeling. Master's Thesis. Harbin Normal University, Harbin, Heilongjiang, China, 2016 [In Chinese].

23. DENG C.L. Theory and Application for Generalized Linear Models. Thesis, Guangxi University, Nanning, Guangxi, China, 2010 [In Chinese].

24. FU Y.Q., ZHANG Z.W., CHEN B.P., LING Z.W. Winter habitat characteristics of red-winged laughing thrush at laojunshan national nature reserve in China. Chinese Journal of Zoology. 46, 48, 2011 [In Chinese].

25. JI R., GAO Z.X., XIE B.Y., LI D.M., ZENG X.C. Prediction on oviposition site selection Locusta migratoria manilensis by logistic model in coastal areas. Acta Ecologica Sinica. 27, 5029, 2007 [In Chinese].

26. QIN A.L., LIU B., GUO Q. S., BUSSMANNN R.W., MA F.Q., JIAN Z.J., XU G.X., PEI S.X. Maxentmodeling for predicting impacts of climate change on the potential distribution of Thuja sutchuenensis, Franch. an extremely endangered conifer from southwestern China. Global Ecology and Conservation. 10 (C), 139, 2017.

27. ELITH J., GRAHAM C.H., ANDERSON R. P., DUDIK M., FERRIER S., GUISAN A., LEHMANN A. Novel methods improve prediction of species' distributions from occurrence data. Ecography, 29, 129, 2006.

28. ELITH J., PHILLIPS S. J., HASTIE T., DUDÍK M., CHEE Y.E., YATES C.J. A statistical explanation of maxent for ecologists. Diversity \& Distributions, 17,43, 2015.

29. HASTIE T., FITHIAN W. Inference from presence-only data, the ongoing controversy. Ecography, 36, 864, 2013.

30. PHILLIPS S.J., ANDERSON R.P., SCHAPIRE R.E. Maximum entropy modeling of species geographic distributions. Ecological Modelling, 190, 231, 2006.

31. XING D.L., HAO Z.Q. The principle of maximum entropy and its applications in ecology. Biodiversity Science, 19 (03), 295, 2011 [In Chinese].

32. KUMAR S., STOHLGREN T.J. Maxent modeling for predicting suitable habitat for threatened and endangered tree Canacomyrica monticola in New Caledonia. Journal of Ecology \& the Natural Environment, 1, 94, 2009.

33. AKBAR M., RAHMUTULLA A., MAHMUT H. Assessing habitat suitability for Cervuselaphus in the Ebinur Lake National Nature Reserve. Acta Ecologica Sinica, 37, 3919, 2017.

34. WORDLEY C.F.R., SANKARAN M., MUDAPPAD., ALTRINGHAM J.D. Landscape scale habitat suitability modelling of bats in the Western Ghats of India: Bats like something in their tea. Biological Conseryation, 191, 529, 2015.

35. YOU J., LENG Z.M., DING J.J. The development report of China contiguous destitute areas. Social Sciences Academic Press: Beijing, Beijing, China, 2013 [In Chinese].

36. LI Y.C., MENG Y.H., ZHANG L.C., YE Q. Analysis of environmental factors on geographical distribution of Chinese chiroptera. Acta Zoologica Sinica. 51 (03), 413, 2005 [In Chinese].

37. LIANG L., DI L.P., ZHANG L.P., DENG M.X., QIN Z.H., ZHAO S.H., LIN H. Estimation of crop LAI using hyperspectral vegetation indices and a hybrid inversion method. Remote Sensing of Environment. 165, 123, 2015.

38. LIANG L., QIN Z.H., ZHAO S.H., DI L.P., ZHANG C., DENG M.X., LIN H., ZHANG L.P., WANG L.J., LIU Z.X. Estimating crop chlorophyll content with hyperspectral vegetation indices and the hybrid inversion method. International Journal of Remote Sensing. 37, 2923, 2016.

39. SHEN Q., LIANG L., LUO X.,LI Y.J., ZHANG L.P. Analysis of the spatial-temporal variation characteristics of vegetative drought and its relationship with meteorological factors in China from 1982 to 2010. Environmental Monitoring and Assessment, 189, 471, 2017.

40. QIAN X.J., LIANG L., SHEN Q., SUN Q., ZHANG L.P., LIU Z.X., ZHAO S.H., QIN Z.H. Drought trends based on the VCI and its correlation with climate factors in the agricultural areas of China from 1982 to 2010. Environmental Monitoring and Assessment, 188, 639, 2016. (SCI)

41. LIANG L., SUN Q., LUO X., WANG J.H., ZHANG L.P., DENG M., DI L.P., LIU Z.X. Long-term spatial and temporal variations of vegetative drought based on vegetation condition index in China. Ecosphere, 8 (8), e01919, 2017.

42. LIANG L., DI L. P., HUANG T., WANG J.H., LIN L., 
WANG L.J., YANG M. Estimation of Leaf Nitrogen Content in Wheat Using New Hyperspectral Indices and a Random Forest Regression Algorithm. Remote Sensing. 10 (12), 1940, 2018

43. UHRIN M., BENDA P., KAŇUCH P. Different responses of attic-dwelling bat species to landscape naturalness. Mammalian Biology. 82, 48, 2017.

44. KELLY R. M., KITZES J., WILSON H., MERENLENDER A. Habitat diversity promotes bat activity in a vineyard landscape. Agriculture Ecosystems and Environment. 223, 175, 2016.

45. GERALD K., MARKUS M. Species-specific barrier effects of a motorway on the habitat use of two threatened forest-living bat species. Biological Conservation. 142, 270, 2009.

46. ZHANG H., GAO J.X., MA M.X., SHAO F.Z., WANG Q., LI G.Y., ZHOU K.X. Influence of road on breeding habitat of Nipponia Nippon based on Maxent model. Chinese Journal of Applied Ecology, 28 (04), 1352, 2017 [In Chinese].

47. LI H., GONG Z.N., ZHAO W.J., GONG H.L. Driving forces analysis of reservoir wetland evolution in Beijing based on logistic regreesion model. Acta Geographica Sinica. 67, 357, 2012 [In Chinese].

48. ZHU G.P., LIU G.Q., BU W.J., GAO Y.B. Ecological niche modeling and its applications in biodiversity conservation. Biodiversity Science, 21 (01), 90, 2013 [In Chinese].

49. BURNHAM K.P., ANDERSON D.R. Model selection and multi-model inference, Springer: New York, New York, USA, 2002.
50. WANG Y.L., LI H., YANG X., GUO Y.L., LI W.D. Prediction of geographical distribution of Vitextrifolia var. simplicifolia under climate change based on the Max Ent model. Acta Prataculturae Sinica, 26, 1, 2017 [In Chinese].

51. YANG X.Q., KUSHWAHA S.P.S., SARAN S., XU J., ROY P.S. Maxent modeling for predicting the potential distribution of medicinal plant, Justicia adhatoda L. in Lesser Himalayan foothills. Ecological Engineering, 51, 83, 2013.

52. SWETS J.A. Measuring the accuracy of diagnostic systems. Science, 240, 1285, 1988.

53. YANGH. F. Analysis on potential distribution area of Xinjiang typical poisonous plant based Maxent and GARP Ecological Niche Model-case of Aconitum leucostomum Vorosch. Master's Thesis. Xinjiang University, Urumchi, the Xinjiang Uygur Autonomous Region, China, 2016 [In Chinese].

54. GAISLER J., ZUKAL J., REHAK Z., HOMOLKA M. Habitat preference and flight activity of bats in a city. Journal of Zoology. 244, 439, 1998.

55. FIELDING A.H., BELL J.F. A review of methods for the measurement of prediction errors in conservation presence/absence models. Environmental Conservation, 24, 38, 1997.

56. BONTADINA F. Conservation ecology in the horseshoe bats Rhinolophus ferrumequinum and Rhinolopus hipposideros. Ph.D. Thesis. University of Bern, Bern, Switzerland, 2002. 
